\title{
APPLICATION OF EXTERNAL FIELDS TO THE DEVELOPMENT OF ALUMINUM-BASED NANOCOMPOSITE AND MASTER ALLOYS
}

\author{
D.G. Eskin ${ }^{1,2}$, S.K. Vadakke Madam ${ }^{1}$, J. Tamayo ${ }^{1}$, S.A. Vorozhtsov ${ }^{2}$, N. Hari Babu ${ }^{1}$, A.B. \\ Vorozhtsov $^{2}$ \\ ${ }^{1}$ Brunel University, BCAST, Uxbridge, UB8 3PH, U.K. \\ ${ }^{2}$ Tomsk State University, Tomsk, 634050 Russia
}

Keywords: Aluminum, Ultrasound, Nanocomposite, Detonation, Microstructure, Tensile properties

\begin{abstract}
Application ultrasonic cavitation and high-energy pulses (e.g. detonation) is a promising way of incorporating reinforcing and grain refining particles in composite and master alloys. This paper gives an overview of research performed recently on the development of new technological approaches and materials with the aim to introduce and distribute nanoparticles in the matrix of aluminum alloys. Both types of particles, introduced externally or formed insitu are discussed. External fields are used for making concentrated master alloys, e.g. Alalumina with subsequent introduction of such a master alloy into the melt with the aid of ultrasonic cavitation; or for direct production of nanocomposites. The examples of implementation include Al-based composites reinforced with nanodiamonds, nanoalumina and nanospinel. The efficiency is illustrated by structure and properties characterization. The research is done within a European program on the application of external fields in liquid metal processing Exomet (EC grant 280421).
\end{abstract}

\section{Introduction}

Metal-matrix composites, especially those reinforced with nanoparticles, enjoy the revival of research and industrial interest caused by the new developments in materials processing and the increased demand for light-weight structural and functional materials. Use of highstrength lightweight structural materials as a replacement for steel and cast iron in transport applications improves fuel efficiency of vehicles thus effectively reducing $\mathrm{CO}_{2}$ emission. Contribution towards reducing carbon emissions plays a crucial role in achieving sustainable development for which a number of different strategies from the transport industry are required. Metal matrix composites (MMC) in which metallic matrices (Al, $\mathrm{Mg}$ ) are reinforced with high strength and high modulus phases, such as carbides $\left(\mathrm{SiC}, \mathrm{B}_{4} \mathrm{C}\right)$, nitrides $\left(\mathrm{Si}_{3} \mathrm{~N}_{4}\right.$, AlN), oxides $\left(\mathrm{Al}_{2} \mathrm{O}_{3}, \mathrm{SiO}_{2}\right)$, as well as elemental materials (C, Si) represent this larger class of light-weight structural materials [1]. The shape of the reinforcement can vary from long microscopic fibers to nano-scale particles and tubes. In this paper we will consider nanoparticle-reinforced MMCs or MMNC where N stand for "nano". Such MMNCs have been shown to offer improvements in strength, ductility, rigidity, temperature stability, wear resistance, reliability and control of physical properties such as density and coefficient of thermal expansion, thereby providing improved engineering performance in comparison to the un-reinforced matrix [1-8].

There are different ways to produce MMCs, e.g. powder metallurgy (limited in size of parts), reactive formation (limited in choice of phases) and liquid metal processing (versatile but challenging). In this paper we will look at the opportunities of using the best features of those technological routes to achieve the desired results. 
The typical liquid metal route for MMNCs is stir mixing of particles. This route usually involves stirring of the melt with an impeller with simultaneous introduction of particles and their distribution by the forced flows. However, the agglomeration of particles and the uneven incorporation into the liquid and, eventually, solid matrix remain the biggest challenge due the following (1) difficult access of the melt to the individual particle surface due to absorbed gas and oxide films; (2) poor wettability of the particles with the liquid phase (melt); (3) agglomeration of fine particles; (4) flotation of particles to the surface or their sedimentation to the bottom of the liquid bath; (5) pushing of particles to grain boundaries during solidification. We will address some of these challenges by using pre-mixed master alloys, in-situ formation of nanoparticles and application of ultrasonic cavitation processing. At contrast to previously published studies, our experiments were performed on substantial volumes of melt and with relatively short processing times.

\section{Experimental}

This paper reports an overview of several experimental activities performed at Brunel University and Tomsk State University within the collaborative European Framework 7 project Exomet. The used materials are summarized in Table 1. The procedures of composite manufacturing were different as described below.

Table 1. Materials used in experiments.

\begin{tabular}{|l|l|l|l|}
\hline Matrix & Particles and sizes (nm) & $\begin{array}{l}\text { Particle } \\
\text { loading (wt\%) }\end{array}$ & $\begin{array}{l}\text { Method of processing and } \\
\text { introduction }\end{array}$ \\
\hline $\mathrm{Al}$ & $\mathrm{Al}_{2} \mathrm{O}_{3},<100 \mathrm{~nm}$ & 5,10 & $\begin{array}{l}\text { Detonation of powder mixture, } \\
\text { master alloys (MA) }\end{array}$ \\
\hline $\mathrm{Al}-4 \% \mathrm{Cu}$ & $\mathrm{Al}_{2} \mathrm{O}_{3},<100 \mathrm{~nm}$ & 0.1 & $\begin{array}{l}\text { Ultrasonic melt processing, from } \\
\text { MA }\end{array}$ \\
\hline $\mathrm{A} 356$ & $\mathrm{C}($ diamond), 1-5 nm & $0.2 ; 1.0$ & $\begin{array}{l}\text { Ultrasonic melt processing, from } \\
\text { particles }\end{array}$ \\
\hline $\mathrm{A} 6082$ & $\mathrm{Al}_{2} \mathrm{O}_{3},<100 \mathrm{~nm}$ & $0.5,1.0$ & $\begin{array}{l}\text { Stirring, ultrasonic melt } \\
\text { processing, from particles }\end{array}$ \\
\hline $\mathrm{Al}-2 \% \mathrm{Mg}$ & $\mathrm{Al}_{2} \mathrm{MgO}_{4}, 300-400 \mathrm{~nm}$ & $0.5,1.2,2.5,6$ & $\begin{array}{l}\text { Stirring, ultrasonic melt } \\
\text { processing, in-situ formation }\end{array}$ \\
\hline
\end{tabular}

The MMNC produced by the addition of lose particles were prepared as follows. The particles were weighed to meet the loading requirement, dried in an electrical furnace at 200$250{ }^{\circ} \mathrm{C}$ and wrapped in two layers of aluminum foil to form a cylindrical rod about $10 \mathrm{~mm}$ in cross section. In the case of nanodiamond particles, 1- $\mu \mathrm{m}$ Al particles were added to the powder mixture. The matrix alloy was melted in an electrical furnace in air in a clay-graphite crucible and the melt was brought up to $750{ }^{\circ} \mathrm{C}$. The typical volume of the melt varied from 1 to $2 \mathrm{~kg}$. The wrapped powders were introduced into the melt in a vortex created by an impeller rotating at a speed of $400 \mathrm{rpm}$ and placed inside the melt at about $1 / 3$ of the crucible height from the bottom. The impeller was made from a $\mathrm{Ti}$ alloy and coated with boron nitride. A weak flow of Ar was administered on top of the melt to prevent oxidation. After this preliminary stage of particle introduction that took typically 10 to $15 \mathrm{~min}$, ultrasonic melt processing was applied at $720-750{ }^{\circ} \mathrm{C}$ for a period of 5 to $15 \mathrm{~min}$ to the formed slurry. The ultrasonic vibrations were delivered to the melt through a Nb horn connected through a $\mathrm{Ti}$ waveguide to a water-cooled 5-kW magnetostrictive transducer. The working frequency was $17.5 \mathrm{kHz}$ and the amplitudes were in the range 20 to $30 \mu \mathrm{m}$ (regime of developed cavitation). After the ultrasonic processing, the melt with particles was poured at $720^{\circ} \mathrm{C}$ into a pre-heated to $200{ }^{\circ} \mathrm{C}$ metallic mold $25 \mathrm{~mm}$ in diameter. 
The concentrated master alloy was prepared using microscopic particles of $\mathrm{Al}$ and nanoparticles of alumina. The particles were mechanically mixed in a defined ratio (5 or 10 $\mathrm{wt} \%$ of nanoparticles) and placed in an aluminum tube $20 \mathrm{~mm}$ in diameter and $300 \mathrm{~mm}$ in length. The tube was closed with both ends with stoppers and placed in a container $60 \mathrm{~mm}$ in diameter with flake TNT uniformly distributed around the tube (860 $\mathrm{g}$ in total). The assembly was placed on a metallic foundation inside an explosion chamber and detonated with a pressed TNT block. Thus formed rods of the master alloy were used in the experiments.

MMNCs prepared with the concentrated master alloy were made using the same procedure as it is described above for particulate additions. The difference was that the master alloy rod was introduced directly into the cavitation zone of the working horn without a stage of mechanical stirring.

In-situ MMNCs were prepared through the reaction of oxide powders with Mg-containing $\mathrm{Al}$ melt. Particles of $\mathrm{SiO}_{2} 2 \mu \mathrm{m}$ in size and up to $5 \%$ in weight were added to an $\mathrm{Al}-1.5 \mathrm{wt} \%$ $\mathrm{Mg}$ melt by mechanical stirring (the same parameters and equipment as described above) at $680-650{ }^{\circ} \mathrm{C}$. Then the mixture was held for $30 \mathrm{~min}$ at $900{ }^{\circ} \mathrm{C}$ to allow for the in-situ formation of spinel $\left(\mathrm{Al}_{2} \mathrm{MgO}_{4}\right)$ with some residual Si going into the matrix. After the end of the reaction the temperature was decreased to $750{ }^{\circ} \mathrm{C}$ and the slurry was treated with ultrasound for 5 min (as described above). Finally the composite was cast at $745{ }^{\circ} \mathrm{C}$ to the said metallic mold.

The matrix alloys were also processed and cast using the same procedure except the addition of particles. These samples were used for comparison. Also some castings were produced following the full procedure but without ultrasonic treatment, to demonstrate the effects of ultrasonication.

The as-cast samples were cut, ground and polished using standard techniques and equipment. The structure was examined using optical (OM), scanning electron (SEM) and transmission electron (TEM) microscopes with the main focus on agglomeration and distribution of particles. Selected castings were machined into tensile samples and tested using a standard tensile machine at a strain rate of $2 \times 10^{-4} \mathrm{~s}^{-1}$. Some samples were also tested at $200{ }^{\circ} \mathrm{C}$. Vickers microhardness was measured with a load of $250 \mathrm{~g}$. At least three samples were tested for each condition and the averaged data are reported.

\section{Results and Discussion}

The application of ultrasonic processing is known to improve the distribution of particles in the liquid metal matrix [9. 10,11]. The physical phenomenon behind this effect of ultrasonic cavitation is the generated pressure and velocity pulses upon imploding of cavitation bubbles. The achieved level of pressure is sufficient to overcome forces that hold agglomerates together and to strip the particles of the absorbed gas to allow the melt full access to the particle surface (improved wetting) [12]. In our experiments this was confirmed as illustrated in Fig. 1a and b. The use of only mechanical stirring may succeed in introduction of particles into the melt but not in their dispersion. The particles remain in large clusters, often associated with porosity. Application of ultrasonic processing in the cavitation regime improves dispersion of particles. Although clustering remains an issue, the particles inside the clusters are well separated (Fig. 1c) and there are also particles embedded into the matrix after solidification (Fig. 1d). This is reflected in the improvement of tensile properties on addition of $1 \mathrm{wt} \% \mathrm{Al}_{2} \mathrm{O}_{3}$ to the AA6082 matrix as compared to the matrix material. The tensile strength at room temperature increased from 160 to $221 \pm 10 \mathrm{MPa}$, the yield strength, from 97 to $142 \pm 4 \mathrm{MPa}$; elongation from 8.7 to $10.9 \pm 1.3 \%$; at $200{ }^{\circ} \mathrm{C}$ the UTS improved from 130 to $178 \pm 9 \mathrm{MPa}$; YS from 91 to $126 \pm 4 \mathrm{MPa}$ at the same elongation of $11 \pm 2.5 \%{ }^{1}$. It should

\footnotetext{
${ }^{1}$ Tensile testing was performed by IMDEA Materials, Spain as a part of the collaborative project Exomet.
} 
be noted that a slight decrease in the grain size is associated with the introduction of particles and ultrasonic processing, e.g. from 210 to $170 \mu \mathrm{m}$.

Application of ultrasonic processing is beneficial also upon introducing nanodiamonds to an aluminum matrix as shown in Fig. 2. The particles (in small clusters) are fairly well distributed inside the matrix, though some porosity and agglomeration was also observed [13]. The addition of nanodiamond particles caused substantial increase of hardness, from $87 \mathrm{HV}$ to $138 \mathrm{HV}$. At the same time only the addition of up to $0.2 \mathrm{wt} \%$ of particles resulted in the significant improvement of tensile properties (Fig 2c); while the larger amount of particles lead to more agglomeration and porosity, and consequently negligible change of the properties as compared to the matrix.

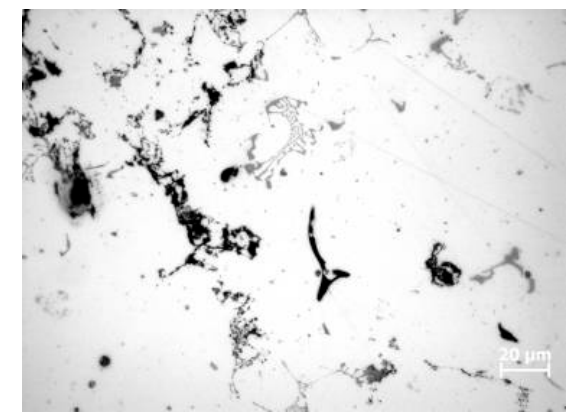

a

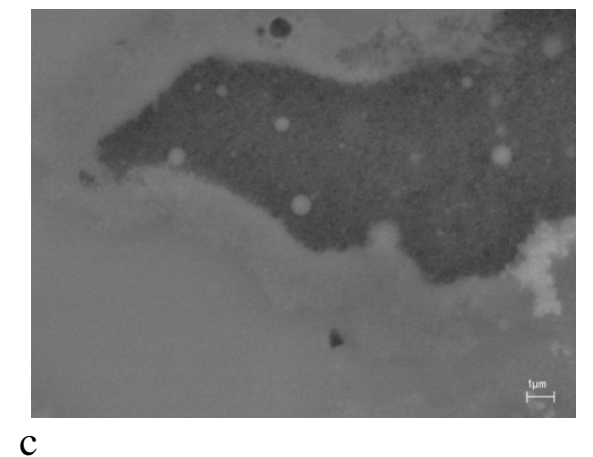

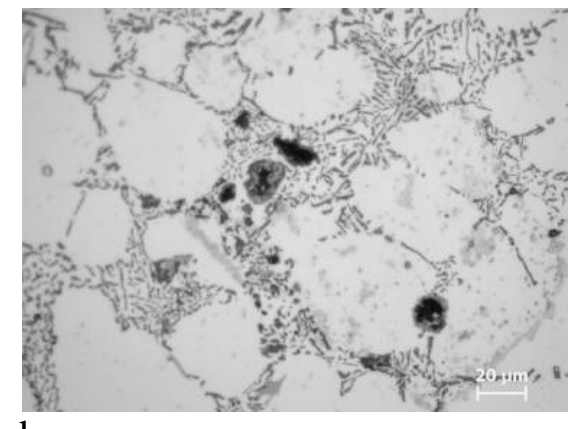

b

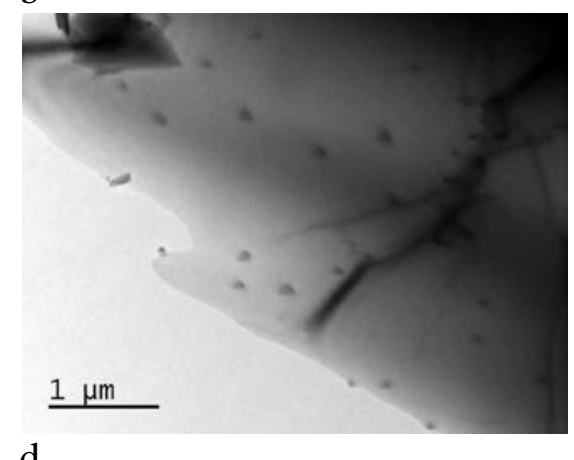

Figure 1. MMNC AA6082-1 wt $\% \mathrm{Al}_{2} \mathrm{O}_{3}$ : a, mechanical stirring, OM; b-d, mechanical stirring with ultrasonic processing (b, OM, c, SEM showing particles in agglomerates; d, TEM showing particles in the matrix (courtesy W. Lefebvre, M. Maunib, University of Rouen)).

Wetting and agglomeration of particles remain difficult to circumference issues even when ultrasonic cavitation is applied. In order to ease the introduction of particles and their distribution two approaches were attempted. One is the application of premixed (and potentially pre-wet) particles in a master alloy that can be introduced into the melt in the same way as a grain-refining rod, but with additional ultrasonic processing for better dispersion. The alumina nanoparticles were well distributed in the sample as shown in Fig. 3. The early results show very good potential of this method. The resultant composite materials based on an $\mathrm{Al}-4 \% \mathrm{Cu}$ alloy showed an increase of the tensile strength from $102 \pm 5$ to $131 \pm 4$ MPa and elongation from $3.6 \pm 1.0$ to $6.3 \pm 1.4 \%$ on introduction of $0.5 \mathrm{wt} \%$ of particles. Similar results were achieved even after $0.1 \mathrm{wt} \%$ addition.

Another way of improving the incorporation of nanoparticles into the matrix is their in-situ formation. Wetting then comes naturally as the reactive wetting, and particles that initially formed in agglomerates reflecting the reaction zones can be dispersed using ultrasonic cavitation and streaming. The first results on in-situ formation of spinel particles in the sizes less than $500 \mathrm{~nm}$ showed that this processing route is quite promising. Figure 4 illustrates this. There is a limitation on the selection of phases that can be obtained as particles and on the matrix composition (a feasible reaction should occur between the liquid matrix and the added particles). In our case study, the presence of $\mathrm{Mg}$ in the liquid aluminum solution was 
the necessary condition for the reaction of added oxides to form spinel. The size of the product particles can be regulated and controlled by the size of added particles and by the time and temperature of the reaction.
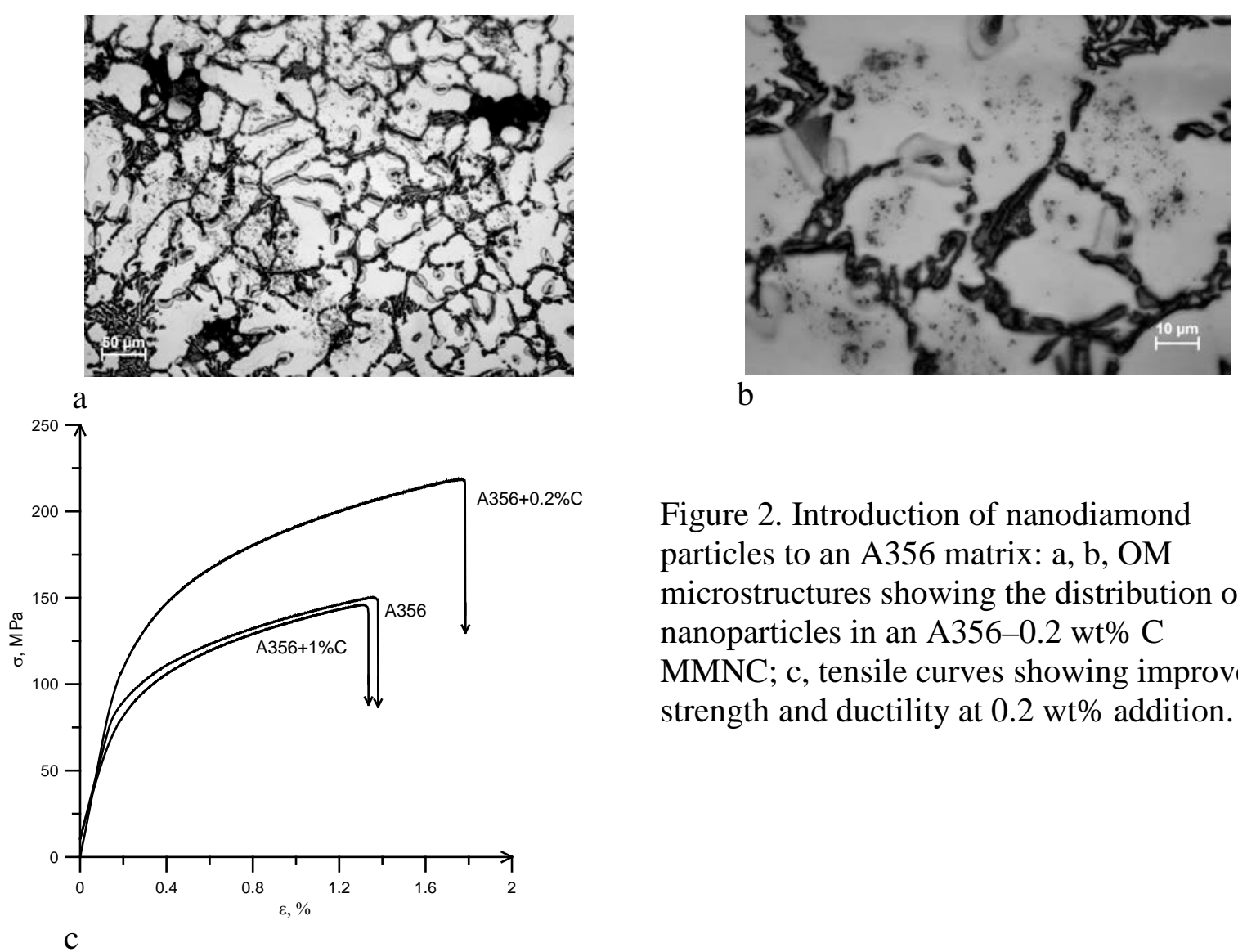

Figure 2. Introduction of nanodiamond particles to an A356 matrix: a, b, OM microstructures showing the distribution of nanoparticles in an A356-0.2 wt\% C MMNC; c, tensile curves showing improved strength and ductility at $0.2 \mathrm{wt} \%$ addition.

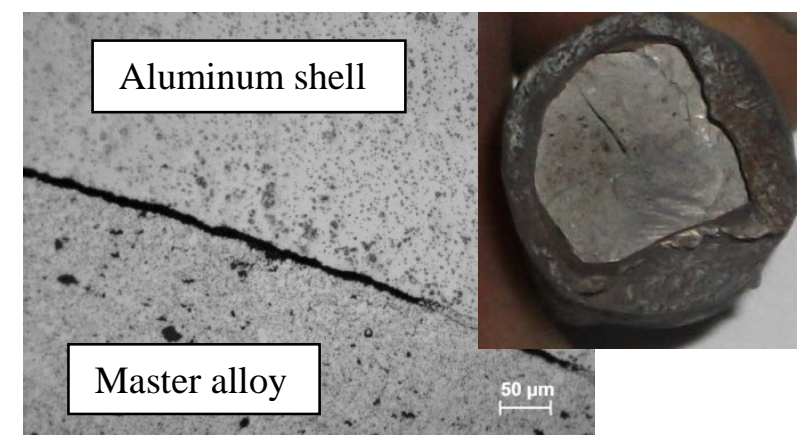

a

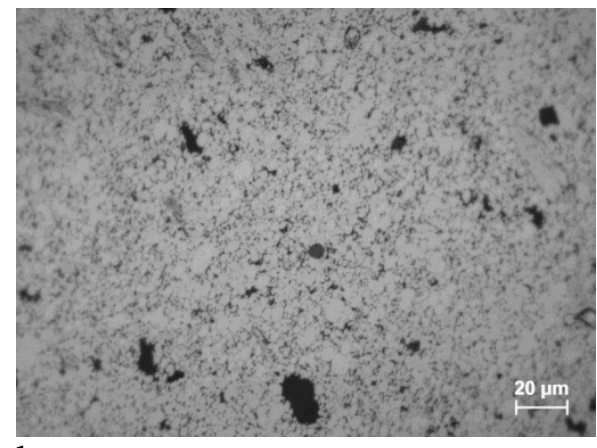

$\mathrm{b}$

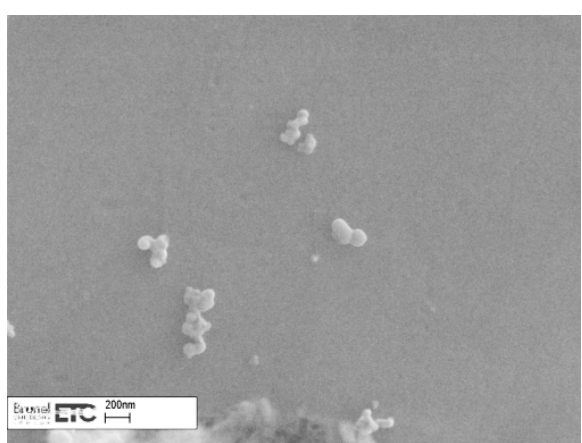

Figure 3. Microstructures of a master alloy $\mathrm{Al}-10 \% \quad \mathrm{Al}_{2} \mathrm{O}_{3}$ (a, general view with the shell; b, enlarged view, OM) and a MMNC with $0.5 \% \mathrm{Al}_{2} \mathrm{O}_{3}$ (SEM).

C 


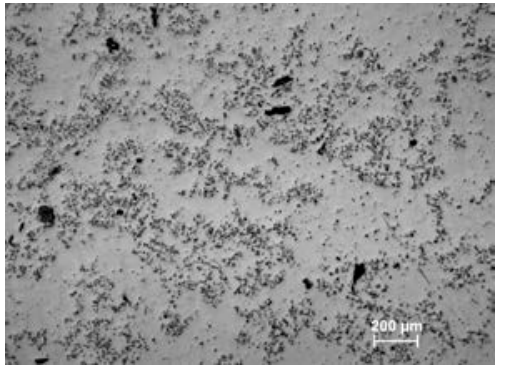

a

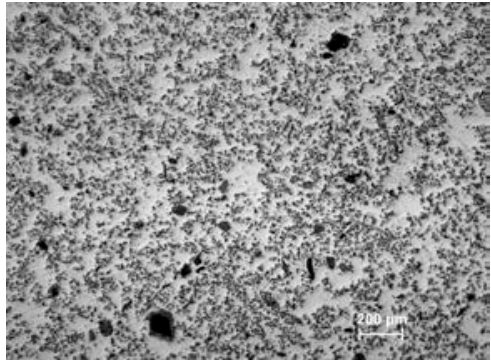

$\mathrm{b}$

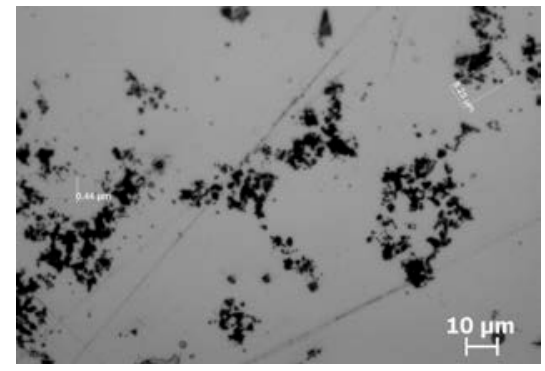

C

Figure 4. Al-Mg-based composite materials with in-situ formed spinel: a, 1.2 wt $\% \mathrm{Al}_{2} \mathrm{MgO}_{4}$ (matrix Al-0.9\% Mg-0.5\% Si); b, $6 \mathrm{wt} \% \mathrm{Al}_{2} \mathrm{MgO}_{4}$ (Al-0.3\% Mg-2.2\% Si); and c, lose agglomerates with individual spinel particles (OM).

\section{Concluding remark}

This overview demonstrates the typical issues on processing metal-matrix composite materials and also show some methods to overcome these issues. The application of ultrasonic melt processing in combination with a concentrated master alloy containing nanaparticles or in-situ formation of nanoparticles seem to be promising routes for manufacturing MMNC, also offering the possibility of the technology upscaling.

\section{Acknowledgement}

The authors acknowledge financial support from the Exomet Project (which is co-funded by the European Commission in the 7th Framework Programme (contract FP7-NMP3-LA-2012280421), by the European Space Agency and by the individual partner organisations).

\section{References}

1. T.W. Clyne and P.J. Withers, An Introduction to Metal Matrix Composites, (Cambridge: Cambridge University Press, 1993).

2. D.J. Lloyd, International Materials Reviews, 39 (1994) 1-23.

3. Y. Yang and X. Li, Journal of Manufacturing Science and Engineering, 129 (2007) 497501.

4. H. Choi et al., Metallurgical and Materials Transactions A, 43 (2012) 738-746.

5. N. Chawla and K. K. Chawla, JOM, 58(11) (2006) 67-70.

6. T.W. Clyne and F. Simancik, eds., Metal Matrix Composites and Metallic Foams, Proc. Euromat 99, (Chichester: Wiley-VCH, 2000).

7. http://mmc-assess.tuwien.ac.at (Data base for MMCs and their assessment for innovations).

8. Z. Fan, P. Tsakiropoulos and A.P. Miodownik, Journal of Materials Science, 29 (1994) 141-150.

9. G.I. Eskin and D.G. Eskin, Ultrasonics Sonochemistry, 10 (2003) 297-301.

10. G. Cao, H. Konishi, X. Li, Materials Science and Engineering A, 486 (2008) 357-362.

11. H. Choi, M. Jones, H. Konishi, X. Li, Metallurgical and Materials Transactions A, 43A (2012) 738-746.

12. G.I. Eskin, D.G. Eskin, Ultrasonic Melt Treatment of Light Alloys Melts, $2^{\text {nd }}$ Edn., (BocaRaton: CRC Press, 2014) 139-144.

13. S. Vorozhtsov, D. Eskin, A. Vorozhtsov, S. Kulkov, Light Metals 2014, ed. J.H. Grandfield, (Warrendale: Wiley/TMS, 2014) 1373-1377. 